\title{
Transformação genética e aplicação de glifosato na microbiota do solo, fixação biológica de nitrogênio, qualidade e segurança de grãos de soja geneticamente modificada
}

\author{
Genetic transformation and the use glyphosate on soil microbial, biological nitrogen fixation, \\ quality and safety of genetically modified soybean
}

\author{
Giani Mariza Bärwald Böhm ${ }^{I}$ Cesar Valmor RombaldiI
}

\section{- REVISÃO BIBLIOGRÁFICA -}

\section{RESUMO}

A soja geneticamente modificada resistente ao herbicida glifosato $\left(G M_{P R}\right)$ é o principal produto da biotecnologia vegetal, considerando-se a evolução da área cultivada e o consumo desse grão. Os Estados Unidos, a Argentina e o Brasil são os maiores produtores de soja $G M_{R R}$. A liberação para cultivo da soja $G M_{R R}$ no Brasil foi efetivada com base, quase que exclusivamente, em trabalhos realizados em outros países, sem a devida validação nas condições edafoclimáticas locais. Nesse contexto, buscou-se coletar e analisar os principais trabalhos que versam sobre impacto ambiental, metabolismo da planta, qualidade e segurança da soja $G M_{R R}$ tratada e não tratada com glifosato. De modo geral, os trabalhos analisados apresentam algumas características comuns: a) avaliam poucas variáveis; e b) inferem, a partir de simulação com ensaios em casa de vegetação ou in vitro, possíveis respostas no cultivo comercial. Embora ainda escassos, os estudos realizados apontam para o fato de que a transformação genética não afeta os microrganismos do solo, nem a fixação biológica de nitrogênio, nem a composição dos grãos. O fator que pode afetar essas variáveis é a aplicação do glifosato no controle de plantas daninhas, ou seja, os riscos de perigo ao ambiente e à segurança dos produtos derivados dessa matéria-prima se devem ao insumo aplicado durante o cultivo, e não à transformação genética propriamente dita.

Palavras-chave: soja transgênica, microrganismos do solo, resíduos de herbicida, isoflavonas.

\section{ABSTRACT}

The genetically modified soybean resistant to glyphosate $\left(G M_{R R}\right)$ is the main product of plant biotechnology, considering the evolution of the area cultivated and the use of this grain. EUA, Argentina and Brazil are the largest producers of $G M_{R R^{*}}$. The release of $G M_{R R}$ soybean cultivation in Brazil was done based on researches that were accomplished in other countries without the validation of the same edaphoclimatic conditions. In this context, the main researches about environmental impact, plant metabolism, quality and safety of $G M_{R R}$ soybean with or without glyphosate application were collected and investigated. In general, the researches investigated showed some similar characteristics: a) few variables were studied; b) simulations in green house or in vitro are used to infer possible response on the field. Although scarce, the researches denoted that the genetic transformation did not affect soil microorganisms, biological nitrogen fixation and composition of grains. The factor which could affect these variables is the glyphosate application in weed control, thus the risk of damage to the environment and the safety of products derived from this raw materialare due to the use of the herbicide during cultivation, and not to the genetic transformation. Key words: Transgenic soybean, soil microorganisms, herbicides residue, isoflavones.

Key words: transgenic soybean, soil microorganisms, herbicides residue, isoflavones.

\section{INTRODUÇÃO}

A soja [Glicine Max (L.) Merr.] geneticamente modificada Roundup Ready $\left(\mathrm{GM}_{\mathrm{RR}}\right)$, resistente ao glifosato, é o produto biotecnológico de

'Departamento de Tecnologia Ambiental, Instituto Federal Sul-rio-grandense, 455, Pelotas, RS. Programa de Pós-graduação em Biotecnologia Agrícola, Universidade Federal de Pelotas (UFPel), Campus Universitário, s/nº , Capão do Leão, RS, Brasil, 96010900. E-mail: gbbohm@terra.com.br. Autor para correspondência.

"Departamento de Ciências e Tecnologia Agroindustrial, Faculdade de Agronomia Eliseu Maciel (FAEM), UFPel, Capão do Leão, RS, Brasil. 
maior importância econômica nos últimos 15 anos, atingindo uma área cultivada de 58,6 milhões de hectares em 2006, o que representa 57\% da área total cultivada com plantas geneticamente modificadas. $\mathrm{O}$ Brasil ocupa o terceiro lugar mundial em área cultivada com soja $\mathrm{GM}_{\mathrm{RR}}$, totalizando 11,5 milhões de hectares (ISAAA, 2006). Na soja $\mathrm{GM}_{\mathrm{RR}}$, a resistência ao herbicida glifosato foi obtida pela introdução, juntamente com a região t-DNA e o gene marcador de seleção, do gene correspondente à isoforma da enzima EPSPS (5enolpiruvilchiquimato-3-fosfato sintase; E.C. 2.5.1.19, CP4 EPSPS), com peptídio sinal, da via do chiquimato, resistente ao glifosato, mantendo ativa a via biossintética de aminoácidos aromáticos nas plantas. Essa via de biossíntese é inibida em genótipos de soja não modificada (NM), sem a isoforma CP4 EPSPS (BUSSE et al., 2001), tendo em vista que o herbicida glifosato [(N-(fosfonometil) glicina, Roundup (Monsanto, St. Loius, MO)], inibe a síntese de aminoácidos aromáticos (fenilalanina, triptofano e tirosina) em plantas (FISHER et al., 1986). O mecanismo de ação do glifosato compreende a inibição da EPSPS, que catalisa a condensação do ácido chiquímico e fosfofenolpiruvato, dando origem à bioconversão de aminoácidos aromáticos. A inibição da via de shiquimato pelo glifosato resulta na acumulação do ácido chiquímico e/ou ácidos hidroxibenzoicos, bem como de ácidos protocatequímicos e/ou ácidos gálicos em espécies de plantas sensíveis (DUKE, 1988) e em Bradyrizobium japonicum (ZABLOTOVICZ \& REDDY, 2004). Efeitos tóxicos do glifosato podem ser atribuídos à inibição da síntese de aminoácidos aromáticos, à exaustão energética resultante do consumo de adenosina trifosfato (ATP) e fosfofenolpiruvato na síntese do chiquimato, ao 3deoxi-D-arabino-heptulose-7-fosfato, aos ácidos hidroxibenzóicos e gálico e à toxidade resultante do acúmulo de moléculas intermediárias na via do shiquimato (FISHER et al., 1986). Desse modo, é possível que haja alterações no metabolismo secundário, incluindo a síntese de compostos fenólicos, que inclui esses metabólitos (REDDY et al., 2000).

A liberação para o cultivo em escala comercial da soja $\mathrm{GM}_{\mathrm{RR}}$ ocorreu a partir de parecer favorável do Comitê Técnico Nacional de Biossegurança (CTNBio) em 24/09/1998, em resposta ao processo enviado pela Monsanto do Brasil Ltda. (nº 01200.002402/98-60). A CTNBio deliberou favoravelmente a liberação, argumentando que, à luz do conhecimento disponível até aquela data, não havia evidências de riscos de perigos ambientais e para a saúde humana e animal, decorrentes do cultivo e consumo da soja $\mathrm{GM}_{\mathrm{RR}}$ do genótipo GTS 40-3-2 e suas progênies (CTNBio, 2007). Nesse contexto, a CTNBio embasou essa afirmativa argumentando que: 1) a soja é uma espécie exótica, de autopolinização, com baixa taxa de alogamia (em torno de 1\%), não possuindo espécies nativas no Brasil passíveis de serem fecundadas com pólen de soja geneticamente modificada; 2) não existe demonstração de efeito pleiotrófico de sua introdução em estudos conduzidos em vários ambientes; 3) com exceção de três espécies de plantas conhecidas como naturalmente tolerantes ao herbicida glifosato (Richardia brasiliensis, Commelina virginica, Spermacoce latifolia), o uso desse herbicida, durante duas décadas, não induziu tolerância em outras espécies de plantas daninhas; 4) não existem evidências de que a utilização do herbicida glifosato no cultivo de soja tenha resultado em efeito negativo sobre a FBN; e 5) não há efeito negativo do cultivo de cultivares derivadas do genótipo GTS 40-32 sobre o perfil e a dinâmica populacional de insetos já associados ao cultivo da soja não modificada.

Além disso, quanto à saúde humana e animal, a CTNBio argumenta que a introdução do gene CP4 EPSPS não altera a composição química da soja, com exceção da própria isoforma CP4 EPSPS, considerada segura quanto aos aspectos toxicológicos e alergênicos. Também foi ressaltado que a utilização da soja $\mathrm{GM}_{\mathrm{RR}}$ e seus produtos derivados na América do Sul, Central e do Norte, na Europa e na Ásia não registraram casos de reação alérgica em pessoas, a menos que já fossem alérgicas à soja não modificada. Não há, entretanto, referências e argumentações quanto ao risco do perigo de resíduos de glifosato e do metabólito ácido aminometilfosfônico (AMPA) em soja $\mathrm{GM}_{\mathrm{RR}}$.

No Brasil, terceiro maior produtor mundial de soja $\mathrm{GM}_{\mathrm{RR}}$, poucos trabalhos têm sido conduzidos visando a estudar possíveis respostas resultantes do cultivo da soja $\mathrm{GM}_{\mathrm{RR}}$ do ponto de vista ambiental, agronômico e de segurança do produto (grão), num mesmo modelo experimental. Além disso, os trabalhos publicados, na sua maioria, em outros países, visaram a avaliar causas e consequências, analisando duas ou três variáveis pontuais (ELMORE et al., 2001; DUKE et al., 2003; ZABLOTOWICZ \& REDDY, 2007) ou limitaramse a ensaios em laboratório (in vitro) (BUSSE et al., 2001; REDDY \& ZABLOTOWICZ, 2003) ou em casa de vegetação (REDDY et al., 2004).

Alguns resultados sobre o efeito do glifosato no cultivo de soja $\mathrm{GM}_{\mathrm{RR}}$ têm sido reportados por diversos grupos de pesquisa, como, por exemplo, o aumento da atividade microbiana (HANEY et al., 2000; BUSSE et al., 2001; HANEY et al., 2002; ARAÚJO et al., 2003a; RATCLIFF et al., 2006), as alterações na 
biomassa microbiana (WARDLE \& PARKINSON, 1990), a toxidade do glifosato para bactérias e fungos (ARAÚJO et al., 2003a; BUSSE et al., 2001), a mineralização do glifosato por Pseudomonas spp. (GIMSING et al., 2004), os resíduos de glifosato e do metabólito ácido aminometilfosfônico (AMPA) em nódulos e no solo (REDDY \& ZABLOTOWICZ, 2003; ARAÚJO et al., 2003a), a redução da FBN (KING et al., 2001; ZABLOTOWICZ \& REDDY, 2007), a redução no conteúdo de leg-hemoglobina nos nódulos (REDDY et al., 2000), além de resíduos de glifosato e AMPA nos grãos (DUKE et al., 2003).

Dessa forma, o objetivo desta revisão visa a contemplar aspectos ambientais, agronômicos e de segurança relacionados com o impacto do cultivo da soja $\mathrm{GM}_{\mathrm{RR}}$, bem como do uso do herbicida glifosato nessa cultura, a fim de sumarizar os principais avanços técnicos científicos nessa temática, amplamente polêmica, mesmo após 10 anos de cultivo.

\section{DESENVOLVIMENTO}

Efeito da transformação genética e da aplicação do glifosato na microbiota do solo

As pesquisas realizadas visando a elucidar o efeito do cultivo da soja $\mathrm{GM}_{\mathrm{RR}}$ e do controle de plantas daninhas com aplicação de glifosato sobre a microbiota de solos têm gerado informações variáveis em função do tipo de solo e das condições de manejo. Assim, por exemplo, verificou-se que a aplicação desse herbicida pode estimular (HANEY et al., 2000) ou inibir (BUSSE et al., 2001) o processo de mineralização de compostos orgânicos no solo. No segundo caso, os efeitos tóxicos do glifosato sobre microrganismos do solo provavelmente se devem à ação dessa molécula sobre a enzima EPSPS de microrganismos (BUSSE et al., 2001).

Em condições controladas de laboratório, foi demonstrado que o glifosato interfere negativamente no desenvolvimento de microrganismos de reconhecida importância no solo, como é o caso de Bradyrhizobium japonicum, bactéria que estabelece relação simbiótica com a soja, fixando nitrogênio biologicamente (KING et al., 2001). Por outro lado, foi verificado que a presença do glifosato pode oferecer vantagens competitivas para microrganismos capazes de degradá-lo. GINSING et al. (2004) investigaram, em condições de laboratório, a mineralização do glifosato e a adsorção do metabólito AMPA em cinco tipos de solos, nos quais observaram que o principal metabolismo de bioconverção de glifosato no solo está associado à mineralização, especialmente, por Pseudomonas spp.
Outros efeitos do herbicida são relatados por HANEY et al. (2002), como o aumento do carbono da biomassa microbiana e da liberação de $\mathrm{CO}_{2}$ (dióxido de carbono) quando o glifosato foi aplicado na dosagem de $840 \mathrm{~g}$ ia ha ${ }^{-1}$ (gramas de ingrediente ativo por hectare) em nove tipos de solos, com diferentes valores de $\mathrm{pH}$ e teores de carbono orgânico e argila, na Georgia e no Texas, Esatdos Unidos. Nesse mesmo estudo, os autores observaram que solos com maior conteúdo de carbono orgânico tendem a mineralizar o glifosato mais rapidamente do que solos com baixo teor de carbono orgânico, possivelmente devido à maior biomassa microbiana no primeiro caso.

A aplicação de glifosato na dosagem de $4320 \mathrm{~g}$ ia ha ${ }^{-1}$ resulta num incremento de 10 a $15 \%$ na liberação de $\mathrm{CO}_{2}$, sugerindo que a microbiota do solo seja capaz de metabolizar o glifosato como uma fonte de carbono (ARAÚJO et al., 2003a). Outro fato relatado nesse trabalho foi a detecção de resíduo de glifosato e AMPA no solo, em maiores concentrações em áreas onde foram realizadas aplicações de glifosato em anos sucessivos. LIPHADZI et al. (2005), ao avaliarem o efeito do herbicida glifosato na dosagem de $1120 \mathrm{~g}$ ia ha $^{-1}$, bem como de outros herbicidas recomendados para a cultura de milho e soja, não detectaram alterações no carbono da biomassa microbiana e na respiração basal. Complementarmente, verificaram que os tratamentos não afetaram a população de nematoides.

Em experimento em campo, estudando o efeito do cultivo de soja $\mathrm{GM}_{\mathrm{RR}}$ e do controle de plantas daninhas, com uma ou duas aplicações de glifosato a $960 \mathrm{~g}$ ia ha-1, foi verificado que houve menor incorporação de carbono pela biomassa microbiana e maior produção de $\mathrm{CO}_{2}$ nas parcelas com aplicação de glifosato (BOHM et al.,2007). Além disso, BOHM et al. (2008) verificaram que o glifosato aplicado em soja $\mathrm{GM}_{R R}$ resulta em resíduo dessa molécula no solo $\left(0,30 \mathrm{mg} \mathrm{kg}^{-1}\right.$ a $\left.0,40 \mathrm{mg} \mathrm{kg}^{-1}\right)$, bem como da molécula de AMPA (1,03mg kg-1 a 1,70mg kg-1). De acordo com SOUZA et al. (1999), os fatores que influenciam a persistência do glifosato estão relacionados com sua adsorção ao solo e com o metabolismo da biodegradação. A degradação do glifosato no solo pode seguir duas vias principais: a primeira consiste na transformação do glifosato em sarcosina por ação da bactéria Agrobacterium radiobacter ou da Enterobacter aeroneges (enzima C-P liase); a segunda rota consiste na transformação do glifosato em ácido aminometilfosfônico (AMPA) sob a ação da bactéria Anthrobacter atrocyaneus e Flavobacterium sp. e do próprio metabolismo da planta (AMARANTE \& SANTOS, 2002). 
Em estudo sobre biodegradação de glifosato (fase adsorvida e fase não adsorvida), EBERBACH (1998) observou que há rápida degradação do glifosato no primeiro dia após a aplicação, seguida de diminuição da velocidade de degradação a partir daí, e que a adsorção restringe a disponibilidade do glifosato para biodegradação ao longo do tempo. Assim, a meia-vida da molécula depende da forma como a molécula está no solo, adsorvida ou não adsorvida. No segundo caso, é de 6 a 9 dias, e a parte adsorvida é de 222 a 835 dias.

Em estudo realizado para avaliar a degradação de alguns herbicidas, ROBERTSON \& ALEXANDER (1994) observaram que o glifosato é mais rapidamente mineralizado quando se repete a aplicação no mesmo solo. Segundo esses autores, o glifosato, quando aplicado repetidamente na mesma área, por vários anos, pode ter a taxa de degradação aumentada, pois os microrganismos presentes podem estar mais adaptados à presença do composto e/ou haver pressão de seleção para microrganismos com enzimas específicas para metabolizá-lo.

A meia-vida do glifosato no solo pode variar em função do tipo de solo, pois, ao avaliar o efeito do glifosato na dosagem de $2160 \mathrm{~g}$ ia $\mathrm{kg}^{-1}$, em amostras de solo Argissolo Vermelho-Amarelo e Latossolo Vermelho, com e sem histórico de aplicação prévia do herbicida em campo, foi verificado que a meia-vida do glifosato foi menor nas amostras do Argissolo do que do Latossolo (ARAÚJO et al., 2003b). Segundo esses autores, esse fato pode estar relacionado à maior quantidade de argila presente em Latossolos, fazendo com que seja mais adsorvido a essas partículas, dificultando a ação microbiana e aumentando a meiavida nesse solo. Outros autores, como CARLISLE \& TREVORS (1988), também reportaram que a meia-vida do glifosato no ambiente é dependente do tipo de solo e da atividade microbiana, podendo variar de uma semana até anos.

Efeito do glifosato sobre a fixação biológica de nitrogênio em soja geneticamente modificada $\left(\mathrm{GM}_{\mathrm{RR}}\right)$

A fixação biológica de nitrogênio (FBN) pode disponibilizar de 65 a $160 \mathrm{~kg} \mathrm{~N} \mathrm{ha}^{-1}$ durante o cultivo da soja, o que pode representar até $100 \%$ do nitrogênio requerido por essa espécie (ZABLOTOWICZ \& REDDY, 2007). Manter a relação simbiótica da planta com as bactérias fixadoras de nitrogênio é importante para se obter uma boa produtividade sem necessidade de incrementar o nitrogênio do solo por fonte externa. A FBN pode ser afetada pela aplicação de glifosato de forma direta por danos às bactérias simbiontes, ou indireta, por afetar a fisiologia da planta hospedeira, reduzindo a eficácia do processo de fixação/absorção. Efeitos do glifosato sobre nodulação, FBN e fisiologia de soja $\mathrm{GM}_{\mathrm{RR}}$ foram estudados por REDDY et al. (2000), KING et al. (2001), REDDY \& ZABLOTOWICZ (2003), ZABLOTOWICZ \& REDDY (2007) e BOHM et al. (2009).

Utilizando o glifosato na dosagem recomendada pelo fabricante, em experimentos realizados em casa de vegetação, foram verificadas alterações em vários parâmetros da nodulação (REDDY et al.,2000 e KING et al.,2001). Por exemplo, REDDY et al. (2000) observaram que glifosato aplicado na dosagem de $1120 \mathrm{~g}$ ia ha ${ }^{-1}$ reduziu em $28 \%$ o número de nódulos, em $47 \%$ a massa de nódulos e em $13 \%$ o conteúdo de leghemoglobina. KING et al. (2001) também observaram que aplicações de glifosato na dosagem de $1680 \mathrm{~g}_{\text {ia }} \mathrm{ha}^{-1}$, num período de cinco a 12 dias após a emergência (estádio V2), reduziram em 33\% a biomassa de nódulos. Porém, aplicações tardias de glifosato, após 18, 25 ou 32 dias, não afetaram a massa de nódulos. Desse modo, o período de aplicação pode afetar o processo de nodulação e, provavelmente, de fixação de N. Complementarmente, REDDY \& ZABLOTOWICZ (2003) testaram o efeito de uma (estádio V2) ou duas aplicações de glifosato na dosagem de $1120 \mathrm{~g}$ ia ha ${ }^{-1}$ (estádios V2 e V4), em condições de experimento em campo, sobre a nodulação, e observaram que o número de nódulos não foi afetado para uma aplicação de glifosato no estádio V2. Porém, duas aplicações (V2 e V4) reduziram a massa de nódulos em aproximadamente $28 \%$, e o conteúdo de leghemoglobina em $10 \%$ em comparação com o tratamento controle, sem herbicida. Esses resultados são contraditórios com os obtidos por KING et al. (2001), segundo os quais as aplicações mais tardias de glifosato não afetam a nodulação.

$\mathrm{O}$ efeito do glifosato sobre as bactérias simbiontes (Bradyrhizobium japonicum) e sobre a redução de acetileno em condições de ensaio em meio de cultura e em casa de vegetação foi citado por ZABLOTOWICZ \& REDDY (2004). Concentrações de glifosato de 0,5 e 1,0 mM inibiram a redução de acetileno a partir de $20 \%$ a $28 \%$ nas cepas mais sensíveis e, nas cepas mais tolerantes, de $8 \%$ a $20 \%$, respectivamente. MALTY et al. (2006) avaliaram o efeito do glifosato sobre três estirpes de Bradyrhizobium elkani (BR 29, INPA 80A e INPA 553A) e uma de Bradyrhizobium japonicum (BR 86) em meio de cultivo com concentrações crescentes do herbicida ( 0 a $454 \mu \mathrm{mol} \mathrm{L}^{-1}$ ). Nesse experimento, foi verificado que o glifosato apresentou efeitos inibitórios sobre o crescimento de Bradyrhizobium em meio de cultura. Além disso, estudaram os efeitos sobre a nodulação da soja em casa de vegetação, em solo que recebeu, antes do 
plantio, dosagens crescentes do herbicida de 600 até $4800 \mathrm{~g}$ ia $\mathrm{ha}^{-1}$. Nesse caso, não houve efeito sobre a nodulação, evidenciando que as respostas são distintas dependendo do modelo de estudo (in vitro ou em casa de vegetação).

Em experimento a campo, conduzido de 2002 a 2004, foi verificado que a nodulação e a FBN são variáveis entre safras, e o glifosato tem pouco efeito sobre essas variáveis se aplicado nas dosagens recomendadas pelo fabricante (até $2240 \mathrm{~g}_{\text {ia ha }}{ }^{-1}$ ). Porém, quando o glifosato foi aplicado em dosagens de $3360 \mathrm{~g}$ ia ha ${ }^{-1}$, foram observadas reduções na FBN, bem como nos teores de $\mathrm{N}$ foliar que reduziram entre $8 \%$ e $13 \%$, e nos grãos que reduziram de $17 \%$ a $32 \%$ (ZABLOTOWICZ \& REDDY, 2007) Esses mesmos autores relatam que as respostas fisiológicas e de rendimento de grãos, com aplicação de glifosato em soja $\mathrm{GM}_{\mathrm{RR}}$, podem variar em função de genótipos, localização geográfica, condições ambientais, tipo de solo, população nativa de Bradyrhizobium, dentre outros fatores.

Em estudo realizado com cultivares de soja modificada e não modificada, foi verificado que a modificação genética da planta não afetou os teores de nitrogênio, nem a massa de nódulos, nem a FBN. Porém, o uso do glifosato implicou a redução da massa de nódulos e da FBN, sugerindo que o uso desse herbicida, por longo período de tempo, poderá reduzir os teores de nitrogênio disponível no solo (BOHM ET al., 2009). O potencial de impacto negativo do glifosato aplicado em soja $\mathrm{GM}_{\mathrm{RR}}$ é também relatado por REDDY et al. (2004), que observaram a formação do AMPA a partir da degradação do glifosato por microrganismos do solo. Em condições de campo, essa formação depende das dosagens do herbicida, do genótipo e das condições edafoclimáticas. Os efeitos do AMPA sobre a nodulação, FBN e assimilação ainda precisam ser estudados.

Outros aspectos relacionados ao impacto ambiental da soja $\mathrm{GM}_{\mathrm{RR}}$ também foram citados por CERDEIRA et al. (2007) e CERDEIRA \& DUKE (2007). CERDEIRA et al. (2007) observaram que altas temperaturas, luminosidade, stress de água e aplicações precoces do glifosato podem diminuir a resistência da soja $\mathrm{GM}_{\mathrm{RR}}$ a esse herbicida, ocasionando clorose, incidência de infecções por Fusarium solani, reduções na FBN, perdas na produtividade e redução de biomassa. Porém, a influência do glifosato sobre a suscetibilidade a doenças em soja $\mathrm{GM}_{\mathrm{RR}}$ é variável, algumas vezes reduzindo e em outras incrementando a suscetibilidade. Os mesmos autores relataram ainda que, em geral, existe pouco efeito negativo do glifosato sobre a microflora, pássaros e artrópodes, e quando isso ocorre se deve ao efeito indireto do glifosato sobre a vegetação do local. CERDEIRA et al. (2007) e CERDEIRA \& DUKE (2007) argumentam que há vantagens no uso de glifosato em relação a outros herbicidas utilizados durante o cultivo da soja $\mathrm{GM}_{\mathrm{RR}}$, pois o glifosato é menos tóxico, a dose letal $\left(\mathrm{DL}_{50}\right)$ do glifosato é $5600 \mathrm{mg} \mathrm{kg}^{-1}$, enquanto que outros herbicidas, como o Imazaquim e Trifluralin, são de $5000 \mathrm{mg} \mathrm{kg}^{-1}$ e Fomesafen é de $2000 \mathrm{mg} \mathrm{kg}^{-1}$; e a aplicação de glifosato no cultivo de soja $\mathrm{GM}_{\mathrm{RR}}$ proporciona o cultivo sem remoção do solo, contribuindo para redução da erosão, compactação do solo e perda de umidade. Entretanto, verificaram que o maior potencial de impacto negativorelacionado ao cultivo de soja $\mathrm{GM}_{\mathrm{RR}}$ com aplicação de glifosato é a possibilidade do surgimento de plantas daninhas resistentes a esse herbicida, além daquelas que já são naturalmente resistentes.

Resíduos de glifosato e ácido aminometilfosfônico e teores de isoflavonas em grãos de soja geneticamente modificada $\left(\mathrm{GM}_{\mathrm{RR}}\right)$

No que concerne aos aspectos relativos ao impacto do manejo da soja $\mathrm{GM}_{\mathrm{RR}}$ com o uso de glifosato sobre a qualidade e segurança dos grãos, verifica-se que a maioria dos estudos foram realizados abordando a composição nutricional dos grãos. Poucas informações foram obtidas frente às prováveis respostas à aplicação do glifosato, quanto aos resíduos da própria molécula e do metabólito AMPA nos grãos, bem como sobre o metabolismo secundário.

O efeito do glifosato na composição de grãos de soja $\mathrm{GM}_{\mathrm{RR}}$ foi avaliado por PADGETTE et al. (1995), TAYLOR et al. (1999), DUKE et al. (2003) e MCCANN et al. (2005). Inicialmente, PADGETTE et al. (1995) avaliaram a expressão do gene CP4 EPSPS em soja $\mathrm{GM}_{\mathrm{RR}}$, na presença e ausência desse herbicida, e verificaram acúmulo similar da proteína CP4 EPSPS em ambas as condições. Na sequência, TAYLOR et al. (1999) compararam duas cultivares de soja $\mathrm{GM}_{\mathrm{RR}}$ (40-32 e 61-67-1), tratadas com glifosato em pré-emergência e em pós-emergência, nas dosagens recomendadas para o produto comercial, com a cultivar parental 'NM' (A 5403), quanto à qualidade geral, incluindo teor de proteínas, fibras, óleos, carboidratos, aminoácidos e isoflavonas. Os resultados demonstraram que nem o genótipo, nem a aplicação do glifosato interferiram nas características nutricionais e funcionais do grão. Segundo esses autores, a via de biossíntese de aminoácidos aromáticos não foi afetada pela modificação genética, resultando em teores de aminoácidos aromáticos similares entre as variedades testadas. Complementarmente, verificaram que o gene 
CP4 EPSPS exerceu sua atividade, tanto na presença, como na ausência de glifosato para a produção de aminoácidos aromáticos.

Outra classe de compostos derivados da via de biossíntese de aminoácidos são as isoflavonas, que têm sido reportadas por possuírem atividades estrogênicas, antioxidantes e hipocolesterolêmicas (GENOVESE et al., 2005). Estudos realizados por DELANNAY et al. (1995) sugerem que o incremento de isoflavonas em soja é resultado de indução por estresses bióticos e abióticos. Assim, se esperaria que a aplicação de glifosato, em soja $\mathrm{GM}_{\mathrm{RR}}$, pudesse resultar em estresses à planta e afetar a síntese dessas moléculas. Porém, essa hipótese não foi confirmada, tendo-se verificado que o tratamento com o herbicida não afeta a síntese e o acúmulo de isoflavonas (TAYLOR et al., 1999; BOHM et al., 2008).

É fato, entretanto, que há significativa variação de concentração de isoflavonas em soja, em função de genótipos, regiões e condições de cultivo, independentemente de ser modificada ou não. GENOVESE et al. (2005), por exemplo, avaliaram 14 variedades de soja NM fornecidas pela Embrapa no ano de 2003, produzidas em Ponta Grossa (Paraná, Brasil), e detectaram concentrações variando de $57 \mathrm{mg}$ $100 \mathrm{~g}^{-1}$ a $188 \mathrm{mg} 100 \mathrm{~g}^{-1}$. Em genótipos cultivados nos Estados Unidos, WANG et al. (2000) reportaram valores de $116 \mathrm{mg} 100 \mathrm{~g}^{-1}$ a $274 \mathrm{mg} 100 \mathrm{~g}^{-1}$. DUKE et al. (2003) observaram valores mais elevados, entre de $361 \mathrm{mg}$ $100 \mathrm{~g}^{-1}$ e $590,3 \mathrm{mg} 100 \mathrm{~g}^{-1}$, em outros genótipos. BOHM et al. (2008), ao compararem os teores médios de isoflavonas de soja $\mathrm{GM}_{\mathrm{RR}}$ (221,08mg $100 \mathrm{~g}^{-1}$ ) e não

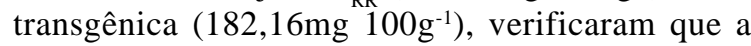
transformação genética não afetou essa variável de forma significativa, o que também havia sido observado por TAYLOR et al. (1999).

Complementarmente, MCCANN et al. (2005) estudaram por três anos consecutivos 25 cultivares de soja $\mathrm{GM}_{\mathrm{RR}}$ tratadas com glifosato em dosagens recomendas pelo fabricante do produto comercial e 25 cultivares não modificadas, ou seja, não tratadas com glifosato. Esses autores verificaram que os teores de componentes nutricionais do grão são similares entre as variedades testadas. Além disso, os teores de lectina, os inibidores de tripsina e a composição de isoflavonas apresentaram variabilidade entre as safras estudadas para todos os genótipos, mas não houve efeito da modificação genética ou da aplicação de glifosato. Assim, pode-se verificar que, de forma geral, segundo esses autores, a aplicação de glifosato em soja $\mathrm{GM}_{\mathrm{RR}}$ não afeta as características nutricionais do alimento, bem como a concentração de moléculas relacionadas com o metabolismo secundário, como as isoflavonas.
Em relação aos resíduos, foram detectados teores de $0,1 \mathrm{a} 1,8 \mathrm{mg} \mathrm{kg}^{-1}$ do principio ativo do glifosato em grãos de soja $\mathrm{GM}_{\mathrm{RR}}$ quando o produto foi aplicado durante os primeiros estádios do cultivo (ARREGUI et al., 2003). DUKE et al. (2003) detectaram teores de 2,18 a 3,08 $\mathrm{mg} \mathrm{kg}^{-1}$ do principio ativo do glifosato e 7,27 a 25,00 $\mathrm{mg} \mathrm{kg}^{-1}$ do metabólito AMPA em grãos de soja $\mathrm{GM}_{\mathrm{RR}}$ tratada com herbicida na dosagem de $1260 \mathrm{~g}$ ia ha $^{-1}$, aplicado 56 dias após o plantio. Esses valores estão abaixo do parâmetro preconizado pela legislação brasileira vigente, que é de $10 \mathrm{mg} \mathrm{kg}^{-1}$. Porém, ressaltase, ainda, que até 1994 o limite máximo permitido de glifosato nos grãos era de $0,2 \mathrm{mg} \mathrm{kg}^{-1} \mathrm{e}$, a partir daí, aumentou-se em 50 vezes esse limite para a soja $\mathrm{GM}_{\mathrm{RR}}$, passando para $10 \mathrm{mg} \mathrm{kg}^{-1}$ (ANVISA, 2007). Destaca-se que esse herbicida pode causar defeitos crônicos ao nascimento em determinadas espécies de animais, quando administrado em doses elevadas e por um período prolongado, embora a ingestão diária aceitável (IDA) por massa corpórea desse composto seja relativamente baixa (IDA $\left.=0,042 \mathrm{mg} \mathrm{kg}^{-1} \mathrm{~d}^{-1}\right)$ (ANVISA, 2007). Os estudos de respostas crônicas em animais alimentados com dietas dentro das concentrações permitidas não mostraram perda de peso ou alterações nas variáveis sanguíneas e do pâncreas ou, ainda, evidência de carcinogenicidade em células humanas. No entanto, estudos realizados com ratos demonstraram perda de peso, descarga nasal e morte de matrizes grávidas, além de desordens digestivas (AMARANTE \& SANTOS, 2002).

Em estudo recente sobre resíduos de glifosato nos grãos da cultivar $\mathrm{GM}_{\mathrm{RR}}$ 'BRS 244RR', com uma e duas aplicações de glifosato na dosagem de 960 g ia ha ${ }^{-1}$ foi verificado que há presença dessa molécula nos grãos, proporcionalmente à dosagem aplicada (BOHM et al., 2008). No tratamento em que se realizou uma aplicação de glifosato, a concentração foi de 19mg $\mathrm{kg}^{-1}$, enquanto que naquele em que foram realizadas duas aplicações a concentração aumentou para $36 \mathrm{mg}$ $\mathrm{kg}^{-1}$. Ao monitorarem-se as concentrações de AMPA, o comportamento foi similar, ou seja, em soja tratada uma vez com glifosato, o resíduo foi de $9 \mathrm{mg} \mathrm{kg}^{-1} \mathrm{e}$, nas parcelas tratadas duas vezes, detectaram-se $12 \mathrm{mg} \mathrm{kg}^{-1}$.

Os teores de glifosato detectados nos grãos por BOHM et al. (2008) são superiores aos teores máximos permitidos pela legislação vigente, bem como superiores aos detectados previamente por DUKE et al. (2003), mesmo que as dosagens utilizadas por esses últimos autores tenham sido maiores. As causas prováveis para essas diferenças ainda não são conhecidas, mas é provável que a metabolização da molécula na planta seja dependente, além do genótipo, das condições edafoclimáticas durante o cultivo, como citado por REDDY et al. (2004). 


\section{CONSIDERAÇÕES FINAIS}

Dentre as espécies geneticamente modificadas liberadas para o cultivo convencional, a soja $\mathrm{GM}_{\mathrm{RR}}$ tem se destacado como o produto da biotecnologia vegetal de maior expressão mundial, ao menos em área cultivada, totalizando, em 2006, 58,6 milhões de hectares. O Brasil se insere nesse cenário como terceiro maior produtor mundial de soja $\mathrm{GM}_{\mathrm{RR}}$, a partir da autorização do cultivo desse genótipo em 1998, pela CTNBio.

Temática polêmica incluindo conceitos de segurança ambiental e do alimento, perpassando por discussões éticas, de soberania científico-tecnológica, de dependência econômica e inclusive ideológica, ainda é elemento de dúvidas e discussões. Nesta revisão, observa-se que a liberação do cultivo no Brasil foi embasada em trabalhos consistentes, mas, na grande maioria, realizados em condições edafoclimáticas distintas dos ecossistemas de cultivo de soja no Brasil. Afora isso, há aspectos técnico-científicos a serem esclarecidos: 1) o efeito da transformação genética da soja $\mathrm{GM}_{\mathrm{RR}}$ no ambiente e na segurança dos produtos à base desse grão; e 2) o efeito do insumo associado à soja $\mathrm{GM}_{\mathrm{RR}}$ e ao glifosato sobre essas mesmas variáveis.

Nessa compilação de dados, observou-se que há consenso de que a transformação genética realizada pela introdução do gene CP4 EPSPS e do gene de seleção não afeta a microbiota do solo, a fixação do nitrogênio, a composição físico-química básica (teor de proteínas, extrato etéreo, carboidratos e minerais), nem o teor de isoflavonas dos grãos. A única alteração detectada é a presença da proteína CP4 EPSPS, o que é absolutamente normal, tendo em vista que se trata do produto de tradução do gene inserido, sem o qual a planta não seria resistente ao glifosato. Embora grande parte dos trabalhos que geraram essas informações tenham sido realizados em outros países (TAYLOR et al., 1999; DUKE et al., 2003; MCCANN et al., 2005; ZABLOTOWICZ \& REDDY, 2007), há relatos e dados consistentes de equipes brasileiras, confirmando, em parte ou na totalidade, esse comportamento nas condições locais (ARAÚJO et al., 2003a; CERDEIRA et al., 2007; BOHM et al., 2008). No entanto, não há unanimidade quanto ao efeito do cultivo de soja $\mathrm{GM}_{\mathrm{RR}}$, com a aplicação do herbicida glifosato, sobre o impacto ambiental, a fixação biológica de nitrogênio e a segurança dos grãos. Nesse caso, dependendo do solo, da região, das condições de cultivo (a campo, em casa de vegetação, em vasos ou in vitro), das dosagens e da época de aplicação do glifosato, pode ou não haver efeito do herbicida sobre o comportamento biológico do solo na FBN e a presença de resíduos de glifosato no solo e nos grãos.
No entanto, detalhadamente, há significativas controvérsias entre os resultados de trabalhos que estudaram o efeito da aplicação de glifosato em soja $\mathrm{GM}_{\mathrm{RR}}$ sobre os resíduos dessa molécula e do metabólito AMPA nos grãos. A priori, de acordo com a recomendação técnica dos produtos registrados junto ao Ministério da Agricultura, Pecuária e Abastecimento (MAPA), respeitando as dosagens, a tecnologia de aplicação e o período de carência, não deverá haver problemas com resíduos acima dos teores permitidos pela legislação vigente, que é de $10 \mathrm{mg} \mathrm{kg}^{-1}$, ou seja, 50 vezes maior do que permitido até 1994 . Avaliando-se os trabalhos que versam sobre essa problemática, há evidência de que, respeitados esses pressupostos, os resíduos de glifosato nos grãos mantêm-se abaixo dos limites máximos (ARREGUI et al., 2003; DUKE et al., 2003). Outros trabalhos, inclusive realizados no Brasil (BOHM et al., 2008), demonstram que há risco significativo do perigo de resíduos nos grãos. É o caso da soja $\mathrm{GM}_{\mathrm{RR}}$, cultivada em duas safras (2005/2006 e 2006/2007), com aplicações do glifosato dentro das recomendações técnicas, que apresentaram resíduos acima do limite máximo. Tal fato também foi observado pelos mesmos autores, que coletaram grãos em propriedades agrícolas brasileiras, e o problema foi confirmado.

Frente a essa situação, recomenda-se a realização de experimentos em cada região de produção, em anos sucessivos, em condições de campo, de modo a obterem-se as reais respostas à aplicação de glifosato na soja $\mathrm{GM}_{\mathrm{RR}}$. Essa afirmativa é feita em função de que a maioria dos trabalhos encontrados abordou a problemática em apenas uma safra, ou em condições de simulação (casa de vegetação, vasos, in vitro), ou avaliando apenas algumas das variáveis citadas nesta revisão. Além disso, embora haja citações de que o problema não existe (DUKE et al., 2003; CERDEIRA \& DUKE, 2007), há risco de ocorrência de perigos ambientais e de segurança dos grãos de soja $\mathrm{GM}_{\mathrm{RR}}$, associados à aplicação do herbicida e não à transformação genética (BOHM et al., 2008).

Em síntese, os estudos realizados apontam para o fato de que a transformação genética não afeta os microrganismos do solo, nem a fixação biológica de nitrogênio, nem a composição dos grãos. $\mathrm{O}$ fator que pode afetar essas variáveis é a aplicação do glifosato no controle de plantas daninhas, ou seja, os riscos de perigo ao ambiente e à segurança dos produtos derivados dessa matéria-prima se devem ao insumo aplicado durante o cultivo, e não à transformação genética propriamente dita. 


\section{REFERÊNCIA}

AMARANTE, O.P.; SANTOS, T.C.R. Glifosato: propriedades, toxicidade, usos e legislação. Química Nova, São Paulo, v.25, n.4, p.589-593, 2002.

ANVISA- Agência Nacional de Vigilância Sanitária. Capturado em: 14 fev. 2007. Online. Disponível na Internet em: <http:/ /www.anvisa.gov.br>.

ARAÚJO, A.S.F. et al. Effect of glyphosate on the microbial activity of two Brazilian soils. Chemosphere, Oxford, v.52, p.799-804, 2003a.

ARAÚJO, A.S.F. et al. Biodegradação de glifosato em dois solos brasileiros. Pesticidas: R. Ecotoxicol. e Meio Ambiente, Curitiba, v.13, p.157-164, 2003b.

ARREGUI, M.C. et al. Monitoring glyphosate residues in transgenic glyphosate-resistant soybean. Pest Management Science, v.60, n.2, p.163-166, 2003.

BOHM, G.M.B. et al. Glyphosate- and imazethapyr-induced effects on yield, nodule mass and biological nitrogen fixation in field-grown glyphosate-resistant soybean. Soil Biology \& Biochemistry, Oxford, v.41, n.2, p.420-422, 2009.

BOHM, G.M.B. et al. Resíduos de glifosato e ácido aminometilfosfônico, e teores de isoflavonas em soja BRS 244 RR e BRS 154 cultivadas em planossolo. Revista Brasileira de Ciência e Tecnologia de Alimentos, Campinas, v.28, supl, p.192-197, 2008.

BOHM, G.M.B. et al. Efeito do controle de plantas daninhas na biomassa e atividade microbiana em planossolo cultivado com soja BRS 244RR. Revista Brasileira de Agrociência, Pelotas, v.13, n.4, 2007.

BUSSE, M.D. et al. Glyphosate toxicity and the effects of long-term vegetation control and soil on soil microbial communities. Soil Biology and Biochemistry, Oxford, v.33, p.1777-1789, 2001

CARLISLE, S.M.; TREVORS, J.T. Glyphosate in the environment. Water, Air, Soil Pollution, v.39, p.409-420, 1988.

CERDEIRA, A.L. et al. Review of potencial environmental impacts of transgenic glifosate-resist ant soybean in Brazil. Journal of Environmental Science and Health Part B, v.42, p.539-549, 2007.

CERDEIRA, A.L.; DUKE, S.O. Environmental impacts of transgenic herbicide-resistant crops. CAB Reviews: Perspectives in Agriculture, Veterinary Science, Nutrition and Natural Resources, v.2, n.033, 2007.

CTNBio- Comitê Técnico Nacional de Biossegurança. Capturado em: 15 abr. 2007. Online. Disponível na Internet em: <http:// www.ctnbio.gov.br/index.php/content/view/3664.html>.

DELANNAY, X. et al. Yield evaluation of a glyphosate-tolerant soybean line after treatment with glyphosate. Crop Science, Madison, v.35, p.1461-1467, 1995.

DUKE, S.O. et al. Isoflavone, glyphosate, and aminomethylphosphonic acid levels in seeds of glyphosate- treated, glyphosate-resistant soybean. Journal of Agricultural and Food Chemistry, Columbus, v.51, n.1, p.340-344, 2003.

DUKE, S.O. Glyphosate. In.: KEARNEY, P.C.; KAUFMAN, D.D. (Eds). Herbicides: chemistry, degradation, and mode of action. Dekker: New York, 1988. V.3, p.1-70,

EBERBACH, P.L. Applying non-steady-state compartmental analysis to investigate the simultaneous degradation of soluble and sorbed glyphosate (N-phosphonomethyl) glycine in four soils. Pesticide Science, Chichester, v.52, p.229-240, 1998.

ELMORE, R.W. et al. Glyphosate-resistent soybean cultivar response to glyphosate. Agronomy Journal, Madison, v.93, p.404-407, 2001.

FISHER, R.S. et al. Comparative action of glyphosate as a trigger of energy drain in Eubacteria. Journal Bacteriol, v.168, p.1147-1154, 1986.

GENOVESE, M.I. et al. Isoflavone profile and antioxidant activity of Brazilian soybean varieties. Food Science and Technology International, Londres, v.11, n.3, p.205-211, 2005.

GIMSING, A.L. et al. Chemical and microbiological soil characteristics controlling glyphosate mineralisation in Danish surface soils. Applied Soil Ecology, v.27, p.233-242, 2004.

HANEY, R.L. et al. Bioremediation and biodegradation: effect of roundup ultra on microbial activity and biomass from selected soils. Journal Environmental Quality, Madison, v.31, p.730-735, 2002.

HANEY, R.L. et al. Effect of glyphosate on soil microbial activity and biomass. Weed Science, Champaign, v.48, p.8993, 2000.

ISAAA- International Service for the Acquisition of Agri-biotech Applications - Global Status of Commercialized Biotech/GM Crops: 2006. Capturado em: 15 maio 2007. Online. Disponível na Internet em: <http://www.isaaa.org/Resources/Publications/ briefs/35/executivesummary/default.html>.

KING, C.A. et al. Plant growth and nitrogenase activity of glyphosate-tolerant soybean in response to foliar glyphosate applications. Agronomy Journal, Madison, v.93, p.79-186, 2001.

LIPHADZI, K.B. et al. Soil microbial and nematode communities as affected by glyphosate and tillage practices in a glyphosate-resistant cropping system. Weed Science, Champaign, v.53, n.4, p.536-545, 2005.

MALTY, J.S. et al. Efeitos do glifosato sobre microrganismos simbiotróficos de soja, em meio de cultura e casa de vegetação. Revista Agropecuária Brasileira, Brasília, v.41, n.2, p.285291, 2006.

MCCANN, M.C. et al. Glyphosate-tolerant soybeans remain compositionally equivalent to conventional soybeans (Glycine max L.) during three years of field testing. Journal of Agricultural and Food Chemistry, Columbus, v.53, p.53315335, 2005. 
PADGETTE, S.R. et al. Development, identification, and characterization of a glyphosate-tolerant soybean line. Crop Science, Madison, v.35, p.1451-1461, 1995.

RATCLIFF, A.W. et al. Changes in microbial community structure following herbicide (glyphosate) additions to forest soils. Applied Soil Ecology, v.34, p.114-124, 2006.

REDDY, K.N et al. Aminomethylphosphonic acid, a metabolite of glyphosate, causes injury in glyphosate-treated, glyphosateresistant soybean. Journal of Agricultural and Food Chemistry, Columbus, v.52, n.16, p. 5139-5143, 2004.

REDDY, K.N. et al. Effect of glyphosate on growth, chlorophyll, and nodulation in glyphosate-resistant and susceptible soybean (Glycine max) varieties. Journal New Seeds, v.2, p.37-52, 2000.

REDDY, K.N.; ZABLOTOWICZ, R.M. Glyphosate-resistan soybean response to various salts of glyphosate and glyphosate accumulation in soybean nodules. Weed Science, Champaign, v.51, p.496-502, 2003.

ROBERTSON, B.K.; ALEXANDER, M. Growth-linked and cometabolic biodegradation: possible reason for occurrence or absence of accelerated pesticide biodegradation. Pesticide Science, Chichester, v.41, p.311-318, 1994.
SOUZA, A.P. et al. Respiração microbiana do solo sob doses de glyphosate e de imazapyr. Planta Daninha, Viçosa, v.17, p.387-398, 1999.

TAYLOR, N.B. et al. Compositional analysis of glyphosatetolerant soybeans treated with glyphosate. Journal of Agricultural and Food Chemistry, Columbus, v.47, p.44694473, 1999.

WANG, C. Isoflavone content among maturity group 0 to II soybeans. Journal of the American Oil Chemists' Society, v.77, p.483-487, 2000

WARDLE, D.A; PARKINSON, D. Effects of three herbicides on soil microbial biomass and activity. Plant and Soil, Dordrecht, v.122, p.21-28, 1990.

ZABLOTOWICZ, R.M.; REDDY, K.N. Impact of glyphosate on the bradyrhizobium japonicum symbiosis with glyphosateresistant transgenic soybean: a minireview. Journal Environmental Quality, Madison, v.33, p. 825-831, 2004.

ZABLOTOWICZ, R.M.; REDDY, K.N. Nitrogenase activity, nitrogen content, and yield responses to glyphosate in glyphosate-resistant soybean. Crop Protection, v.26, p.370376, 2007. 